\title{
The role of patient advocacy/parent support groups
}

\author{
J G Hall, MD \\ Departments of Medical Genetics and Pediatrics, University of British Columbia and BC Children's Hospital, Vancouver, British Columbia, Canada
}

Corresponding author: J G Hall (jhall@cw.bc.ca)

\begin{abstract}
Parent support/patient advocacy groups for rare genetic disorders have emerged as an important force. They provide information, encourage research (both by participation in research and by raising money for research), give families and affected family members the opportunity to learn from each other, and open the way for social and intellectual interaction between families, affected individuals, researchers and healthcare providers. New IT technologies increase the opportunities for collaboration and information exchange around the world. These groups have become an important resource for families, genetic counsellors and medical/clinical genetic professionals.
\end{abstract}

S Afr Med J 2013;103(12 Suppl 1):1020-1022. DOI:10.7196/SAMJ.6976

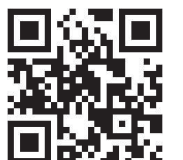

Since the late 1960s, hundreds of parent support and patient advocacy groups related to specific disorders have been formed. ${ }^{[2]}$ Many of these disorders have a genetic basis, and with the amazing advances in human/medical genetics, more and more issues and ideas, opportunities and potential therapies have become available. With the advent of the internet, social networking and universal e-mail, the potential for family-to-family communication has expanded exponentially. The opportunity to learn from other families and other patient advocacy groups is enormous. The real challenge has been one of determining the accuracy of the information that is available. That is where knowledgeable healthcare professionals become important - to give expert advice.

Groups have sprung up all over the globe. If they are related to the same disorder, interested individuals communicate freely, sharing medical information, diagnostic information, practical aspects about living with the disorder, the natural history and potential therapies, all in new and engaging ways. ${ }^{[3-4]}$

Such groups are usually started by a single individual seeking information, who reaches out to others. It may be an affected person, a parent, a grandparent, or another family member. Often a group starts when two or three people 'connect' and share

By the second decade of the 21st century, most clinical geneticists are both aware of and involved in patient advocacy and parent support groups. During my training in medical genetics, I worked with Dr Victor McKusick, just as he was becoming involved with Little People of America (LPA), to study chondrodysplasia. In many ways, LPA is a particularly good model for how special interest patient support groups function. I gained additional insight in 1995 when I was the Philip von Wielligh Lecturer in South Africa, at Trefor Jenkins' invitation, visiting Pretoria, Durban, Cape Town and Johannesburg. My visit was sponsored by the Southern African Inherited Disorders Association (SAIDA), which had been formed 20 years earlier in 1975, primarily to undertake Tay-Sachs carrier screening. However, once families became involved, they realised there was a much broader spectrum of genetic disorders - each relatively rare - and they saw the power of their collaboration. ${ }^{[1]}$ Each family, of course, is interested in 'their disorder', but there is so much they can learn from each other. information, experiences and ideas. They often evolve into more formal organisations with by-laws and non-profit status, and with healthcare professionals/medical advisors in partnership. Most of these organisations are totally voluntary, although as they grow and move into fundraising they may require an executive officer and after years of successful operation may have an office and staff..$^{[5]}$

\section{Parent support group activities}

The types of activities of parent support groups include:

- Information sharing through public and family education, often involving conferences, workshops and meetings where networking can take place; a newsletter that provides information, new research results, personal experiences, fundraising opportunities, etc.; and postings on websites of all types of information, together with references

- Most groups support and encourage research on 'their' disorder by participating in research studies, often assisting in the study design (as part of the new community-based research process). They may also solicit volunteers and control subjects, help to collect the data, and even help with the analysis. Some groups raise money to support both basic and clinical research as well.

- Most groups are interested in developing and updating guidelines for care of individuals affected with the disorder (which of course depends on the results of the research). Care guidelines involve knowledge about the natural history of the disorder and the appropriate therapies and management.

- Most groups have social events, including meeting other families. Such events provide emotional support and the opportunity to meet other affected individuals, particularly of different ages.

- Some groups take on the role of advocating for research concerning new therapies for 'their' disorder. Most of these disorders fit into the 'rare disease' category. ${ }^{[6 \cdot 9]}$ Often an organisation will bring together a surprisingly large number of affected individuals who are willing to take part in research projects. The advocacy can be for research regarding natural history information, for management and care, or for therapy. ${ }^{[1-11]}$ Once some type of therapy is available (symptomatic, corrective, molecular or genetic), the advocacy component may then be related to raising funding for treatment for all affected individuals.

- Many groups take part in creating a registry of affected individuals or a biobank of specimens. ${ }^{[5]} \mathrm{A}$ recent study by Landy et al. ${ }^{[12]}$ surveyed disease advocacy organisations and identified the kinds of research engagement. 
- Finally, because families are highly motivated to learn about 'their' disorder/disease, they use their IT skills to scan and keep track of new medical/research developments, even informing researchers and their physicians about new developments. They also inform members of their group about new developments, leading to improved treatment for the members. Families and affected individuals sometimes make their own hypotheses about cause and effect, often spurring on research studies.

\section{Medical advisors}

Such groups need accurate and reliable medical information, so they usually engage knowledgeable healthcare professionals with whom they work. ${ }^{[13-14]}$ Lin et al. ${ }^{[15]}$ surveyed a group of genetic healthcare professionals and found that $95 \%$ serve on a medical advisory board for one or another patient support group. Most are volunteers without pay, and most have taken part in producing educational materials and guidelines. The concerns of healthcare professionals who volunteer for and support genetic lay advocacy groups focused on: (i) confidentiality regarding affected individuals and their families' medical information and family history; ${ }^{[15-16]}$ (ii) their own potential conflicts of interest; ${ }^{[15]}$ and (iii) any medico-legal liability that might arise. ${ }^{[15]}$

Because of the large number of genetic disorder support groups, alliances between groups have developed in North America and Europe, as happened much earlier in South Africa. These alliances ${ }^{[2-4]}$ bring small groups and groups that have just started out together with more experienced groups so they can learn about organisation, priorities, means of communication, and what works and doesn't work. Most importantly, the newer groups can learn how to deal with the growth of an organisation over time, how to manage interaction with researchers, and how to communicate new information when it becomes available.

\section{Genetic counselling}

Clinical/medical geneticists usually work in medical settings to provide genetic counselling, which is based on the family and affected person's history, ${ }^{[17-18]}$ laboratory studies, and physical examination. In this age of fast-moving information, genetic counselling involves a scan of the literature and recent publications, to be as well informed as possible.

Genetic counselling has been defined as: $:^{[18]}$

- A 'communication process' that deals with human problems associated with the occurrence or risk of recurrence of a genetic disorder in a family. The process involves comprehending the medical facts, including how a diagnosis is made, the probable course of the disorder (natural history), and available management (therapy).

- Appreciation of, and understanding of, the ways in which heredity contributes to the disorder and the risk of recurrence in specific relatives.

- Understanding the alternatives for dealing with the recurrence risk (such as prenatal diagnosis, reproductive options, and other available alternatives including the types of carrier tests that are available or might be developed in the future).

- Helping the family to choose a course of action that is appropriate in view of their risk, their family's goals and their ethical and religious standards.

- Helping the family to act in accordance with that decision, making the best possible adjustment to the diagnosis. The role of the genetic counsellor is helping to identify and deal with the associated feelings, and providing support for the decision(s).

Genetic counselling aims to be non-directive, confidential, and without personal conflict of interest. There are differences in genetic counselling for children and adults that must be considered. In general, it is thought that most definitive decisions can wait for maturity and should be left until it is possible to engage the affected individual in the decision-making process. However, some disorders such as inborn errors of metabolism picked up on newborn screening of course require immediate treatment.

A whole variety of new issues have begun to face the genetic counsellor (as well as the supportive organisations), such as whether to reveal incidental findings, ${ }^{[19]}$ how to engage and warn relatives at risk, ${ }^{[20]}$ and the duty to recontact ${ }^{[2]]}$ and/or to follow up ${ }^{[2]}$ when new research findings could be relevant for the family.

It has become clear through the study of various rare genetic disorders that ethnic origin is important both in assessing risk and in the way in which genetic counselling is provided. ${ }^{[23-24]}$ This is particularly relevant to South Africa, where founder mutations and ethnic group-specific mutations have been identified. Consanguinity increases the risk of autosomal recessive disorders and stillbirths, ${ }^{[25]}$ and advanced parental age clearly increases the risk of new mutations and chromosomal abnormalities. Each family responds differently to these complex issues, and patient support groups help to identify this type of issue.

\section{Rare genetic disorders}

For rare genetic disorders, affected individuals and families generally wish to have guidelines for their healthcare. ${ }^{[26]}$ Many guidelines have been developed and are available through the Canadian College of Medical Genetics, the American College of Medical Genetics, the American Academy of Pediatrics and the European Society of Human Genetics. In addition, some journals specialise in mini-reviews or summaries, such as Clinical Genetics, the European Journal of Human Genetics, the New England Journal of Medicine and The Lancet.

\section{New developments}

The availability of newborn screening raises the possibility of screening for treatable disorders, but also for disorders that had not previously been screened for, and for which therapies are not yet available. ${ }^{[27]}$ The justification for screening for this type of disorder is to provide appropriate counselling for the next pregnancy and give affected individuals the opportunity to participate in research early in the course of the disorder. Family support groups seem to agree with this type of justification.

With the advent of directed gene testing and whole-genome sequencing, direct-to-consumer testing has become available for many disorders. ${ }^{[28]}$ With the goals of commercialising genetics and profit making, all these direct-to-consumer tests have major problems of interpretation and full genetic counselling. This can be a really important issue for families struggling to find a diagnosis.

The advances in genomic medicine have made many new screening techniques available, but the interpretation of these findings is often difficult $^{[20.30]}$ and requires special expertise. For instance, wholegenome sequencing identifies hundreds of new genetic changes between generations, often making interpretation of results extremely difficult. When abnormalities are found with comparative genomic hybridisation array in the affected person, parental studies usually need to be done and even then it is not always clear how to interpret the results. Exomic studies may be equally difficult to interpret. ${ }^{[30]}$

Availability and the cost to healthcare systems become relevant with regard to whether genetic diagnostic tests will actually be available to families. ${ }^{[30]}$ Often molecular diagnostic testing will not be provided by a healthcare-providing group or system, unless making a specific diagnosis will change treatment or reproductive outcomes.

With new forms of testing, a whole range of new ethical issues arise concerning confidentiality and privacy, which of course are important 
to families. Privacy issues tend to interfere with surveillance studies, such as determining the incidence of birth defects in a given country or population (which families of course want to know). Reporting of birth defects to surveillance institutions can interfere with the establishment of frequency of these 'rare' disorders. ${ }^{[6-8]}$ Another important ethical issue is whether children should be allowed to take part in research studies. If they are not, research concerning the childhood aspect of any disorder may be limited.

Educating newly diagnosed families is a real challenge to healthcare providers. Parent support groups and their members are often most helpful, since it involves one affected family talking to another. Parent support groups provide many different types of resources both to medical geneticists and to families with specific diseases.

\section{Progress around the world}

In the almost 20 years that have passed since my visit to South Africa, sponsored at that time by SAIDA, there have been enormous advances in human/medical genetics. Patient advocacy/parent support groups have helped to clarify the way in which this new knowledge should be used. I am very grateful to SAIDA for the opportunity to have got to know and worked with Trefor Jenkins, and to the good families around the world that, through their organisations, support our everimproving provision of care.

1. Jenkins T. Medical genetics in South Africa. J Med Genet 1990;27(12):760-779. [http://dx.doi.org/10.1136/ jmg.27.12.760]

2. Genetic Alliance. Genetic Alliance Disease InfoSearch Inclusion Guidelines. http://www.geneticalliance. org/diseaseinfosearch (accessed 30 May 2012).

3. Unique - The Rare Chromosome Disorder Support Group. http://www.rarechromo.org/html/home.asp (accessed 30 May 2012)

4. International Alliance of Patients' Organizations. Membership Guide. http://www.patientsorganizations. org/iapo_media/Membership\%20Guide\%20Cover.jpg (accessed 30 May 2012).

5. Terry SF Horn EJ Scott I, Terry PF. Genetic alliance registry and biobank: A novel disease advocacy-driven research solution. Per Med 2008;8(2):207-213. [http://dx.doi.org/10.2217/pme.11.1]

6. Schieppati A, Henter JI, Daina E, Aperia A. Why rare diseases are an important medical and social issue. Schieppati A, Henter II, Daina E, Aperia A. Why rare diseases are an important medic

7. Gahl WA, Markello TC, Toro C, et al. The National Institutes of Health Undiagnosed Diseases Program Insights into rare diseases. Genet Med 2012;14(1):51-59. [http://dx.doi.org/10.1038/gim.0b013e318232a005] 8. Knight AW, Senior TP. The common problem of rare disease in general practice. Med J Aus 2006;185(2):82-83

9. Dunkle M, Pines W, Saltonstall PL. Advocacy groups and their role in rare diseases research. Adv Exp Med Biol 2010;686:515-525. [http://dx.doi.org/10.1007/978-90-481-9485-8_28]
10. Ingelfinger JR, Drazen JM. Patient organizations and research on rare diseases. $\mathrm{N}$ Engl J Med 2011;364(17):1670-1671.[http://dx.doi.org/10.1056/NE]Mel 102290]

11. Sharp RR, Landy DC. The financing of clinical genetics research by disease advocacy organizations: A review of funding disclosures in biomedical journals. Am J Med Genet A 2010;152A(12):3051-3056. [http.// dx.doi.org/10.1002/ajmg.a.33767]

12. Landy DC, Brinich MA, Colten ME, Horn EJ, Terry SF, Sharp RR. How disease advocacy organizations participate in clinical research: A survey of genetic organizations. Genet Med 2012;14(2):223-228. [http:// dx doi.org/10.1038/gim.0b013e3182310ba0]

13. Lyon GJ. Personalized medicine: Bring clinical standards to human-genetics research. Nature 2012;482(7385):300-301. [http://dx.doi.org/10.1038/482300a]

14. Vincent C, Davis R. Patients and families as safety experts. CMAJ 2012;184(1):15-16. [http://dx.doi. org/10.1503/cmaj.111311

15. Lin AE, Terry SF, Lerner B, Anderson R, Irons M. Participation by clinical geneticists in genetic advocacy groups. Am J Med Genet A 2003;119A(1):89-92. [http://dx.doi.org/10.1002/ajmg.a.20027]

6. Clarke A. Confidentiality and serious harm in genetics. Eur J Hum Genet 2005;13(4):399. [http://dx.doi. org/10.1038/sje.jhg. 5201349

17. Pyeritz RE. The family history: The first genetic test, and still useful after all those years? Genet Med 2012;14(1):3-9. [http://dx.doi.org/10.1038/gim.0b013e3182310bcf]

18. Biesecker BB. Goals of genetic counseling. Clin Genet 2001;60(5):323-330. [http://dx.doi.org/10.1034/ j.1399-0004.2001.600501.x]

19. Wolf SM, Crock BN, Van Ness B, et al. Managing incidental findings and research results in genomic research involving biobanks and archived data sets. Genet Med 2012;14(4):361-384. [http://dx.doi. org/10.1038/gim.2012.23]

20. Falk MJ, Dugan RB, O'Riordan MA, Matthews AL, Robin NH. Medical geneticists' duty to warn at-risk relatives for genetic disease. Am J Med Genet A 2003;120A(3):374-380. [http://dx.doi.org/10.1002/ ajmg.a.20227]

21. Hunter AG, Sharpe N, Mullen M, Meschino WS. Ethical, legal, and practical concerns about recontacting patients to inform them of new information: The case in medical genetics. Am J Med Genet 2001;103(4):265276. [http://dx.doi.org/10.1002/ ajmg.1568.abs]

22. Esmer C, Urraca N, Carnevale A, Del Castillo V. Patient follow-up is a major problem at genetics clinics. Am J Med Genet A 2004;125A(2):162-166. [http://dx.doi.org/10.1002/ajmg.a.20303]

3. Al-Kassimi M. Cultural differences: Practising medicine in an Islamic country. Clin Med 2003;3(1):52-53. [http://dx.doi.org/10.7861/clinmedicine.3-1-52]

24. Zlotogora J. Knowing the ethnic origin of the patient is important in making a diagnosis. Am J Med Genet 1998;78(4):393-394. [http://dx.doi.org/10.1002/(SICI)1096-8628(19980724)78:4<393::AIDAJMG23>3.0.CO;2-C]

25. Bittles A. Consanguinity and its relevance to clinical genetics. Clin Genet 2001;60(2):89-98. [httt://dx.doi. org/10.1034/j.1399-0004.2001.600201.x]

26. Weaver DD, Baker D, Theobald M, et al. Minimum guidelines for the delivery of clinical genetics services. The Evaluation of Clinical Services Subcommittee, Great Lakes Regional Genetics Group. Am J Hum Genet 1993;53(1):287-289.

27. Hoffman A. The newborn screening translational research network. The ACMG Medical Geneticist 2011; Summer: 6-7.

28. CCMG Ethics and Public Policy Committee, Nelson TN, Armstrong L, et al. CCMG statement on direct-toconsumer genetic testing. Clin Genet 2012;81(1):1-3. [http://dx.doi.org/10.1111/j.1399-0004.2011.01789.x] 2. Gollust SE, Wilfond BS, Hull SC. Direct-to-consumer sales of genetic services on the Internet. Genet Med 2003;5(4):332-337. [http://dx.doi.org/10.1097/01.GIM.0000076972.83711.48]

30. Biesecker LG. Opportunities and challenges for the integration of massively parallel genomic sequencing into clinical practice: Lessons from the ClinSeq project. Genet Med 2012;14(4):393-398. [http://dx.doi. org/10.1038/gim.2011.78]

Accepted 14 August 2013. 